\title{
Portable Document Format File Containing the Surface Models to Learn the Stereoscopic Shape of Foot Muscles
}

\author{
Archivos en Formato de Documento Portátil con Modelos de Superficie \\ para Aprender la Forma Estereoscópica de los Músculos del Pié
}

Hae Gwon Jang*; Min Suk Chung** \& Dong Sun Shin***

JANG, H. G.; CHUNG, M. S. \& SHIN, D. S. Portable document format file containing the surface models to learn the stereoscopic shape of foot muscles. Int. J. Morphol., 33(4):1287-1292, 2015.

SUMMARY: We intended to present a portable document format (PDF) file containing stereoscopic surface models of the foot. While other surface models are subjectively drawn based on anatomical knowledge, our models are reconstructed from high quality sectioned images. Unlike other models, ours in the complimentary PDF file can also be saved on individual user computers to be manipulated off-line. The skin, 27 bones, 24 muscles, and 19 ligaments in the foot were delineated on a male cadaver's sectioned images from the Visible Korean project. After stacking the outlines of the structures, other than those of the ligaments, surface reconstruction was performed. The resultant surface models were placed in a PDF file, in which the models could be superimposed on either the corresponding sectioned images or the color-filled outline images. PDF bookmarks were established to exhibit the groups of foot muscles conveniently. The PDF file prepared in this research is likely to be very useful for comprehension of the topographic anatomy of the foot muscles. The models it contains can be extracted by other researchers for their own virtual dissection or surgery visualization of foot as desired.

KEY WORDS: Visible Human Projects; Foot; Muscles; Three-dimensional imaging; Computer-assisted image processing; User-computer interface.

\section{INTRODUCTION}

The muscles of the foot are classified as either extrinsic or intrinsic. The extrinsic muscles are categorized into the three groups passing inside the extensor, flexor, and fibular retinacula that belong to muscles in the anterior, posterior, and lateral regions of leg, respectively. The intrinsic muscles are also sub-divided into the dorsum of foot and the first, second, third, fourth layers of sole. In this way, foot muscles are well classified; they are also systematically named in Latin (Table I) (Moore et al., 2013). However, their stereoscopic configuration is hard to comprehend by use of an anatomy atlas. The solution of choice is to dissect a cadaver foot. Yet most students in allied health professional education, such as physical therapy students, are not allowed to approach cadavers. Even medical students and clinicians are not free from place and time constraints when using cadavers. Consequently, plastic models of the foot have been used as a substitute.
However, these models are expensive for private possession and have restrictions in terms of the possibilities for disassembling and reassembling the individual foot muscles.

At present, three-dimensional (3D) surface models of the foot bones and muscles are available for personal computer use. While the prevailing models are drawn in a way that is artistic and subjective, our models are made of a cadaver's sectioned images to be scientific and objective. The purpose of this work is to distribute more profitable models, contained in a portable document format file. Unlike other products, the PDF file, which is downloadable free of charge, can also be manipulated off-line to display the wanted surface models in real time (Ruthensteiner \& Hess, 2008; Kumar et al., 2010; Phelps et al., 2012; Shin et al., 2012a, 2012b, 2013; Park et al., 2013; Kim et al., 2014).

\footnotetext{
* Graduate School of Information and Communication, Ajou University, Suwon, Republic of Korea.

** Department of Anatomy, Ajou University School of Medicine, Suwon, Republic of Korea.

**** Department of Orthopaedic Biomaterial Science, Graduate School of Medicine, Osaka University, Osaka, Japan.

This work was supported by National Research Foundation of Korea (NRF) Grant funded by the Korean Government (MSIP) (N² 2015R1A5A7037630).
} 


\section{MATERIAL AND METHOD}

Segmentation. In the Visible Korean project, sectioned images (intervals $0.2 \mathrm{~mm}$ ) were acquired from an entire male cadaver (33 years old; statue $1.64 \mathrm{~m}$; weight $55 \mathrm{~kg}$ ) (Park et al., 2005). We selected 202 images (intervals $1 \mathrm{~mm}$ ) from the distal part of the tibia and fibula to the end of the foot. The images were opened on Photoshop CS5 version 12 (Adobe Systems, Inc., San Jose, CA) to be saved as Photoshop document (PSD) files. Our interest was the left-sided foot, beyond which excessive margins were cropped to reduce the resolution from 3,040 X 2,008 to 992 X 817 .

We used pre-existing segmented images, in which the outlines of 33 structures (skin, bones, and muscles) of the left foot had been drawn (Shin et al., 2012c). These outlines, placed on the new trimmed sectioned images, were confirmed and edited if necessary. Additional muscles and identifiable ligaments in the foot were delineated. The outlines were then filled with different colors according to the individual components.

Surface reconstruction. We decided to carry out surface reconstruction of the skin, bones, and muscles, excluding the ligaments (Table I). Only color-filled outlines excluding the sectioned images were saved as bitmap (BMP) files. On Mimics version 10 (Materialise, Leuven, Belgium), 202 BMP files were placed in a Mimics file. After stacking the categorized colors of each structure, surface reconstruction was successfully accomplished. In each surface model, the accumulated outlines were removed and the triangular

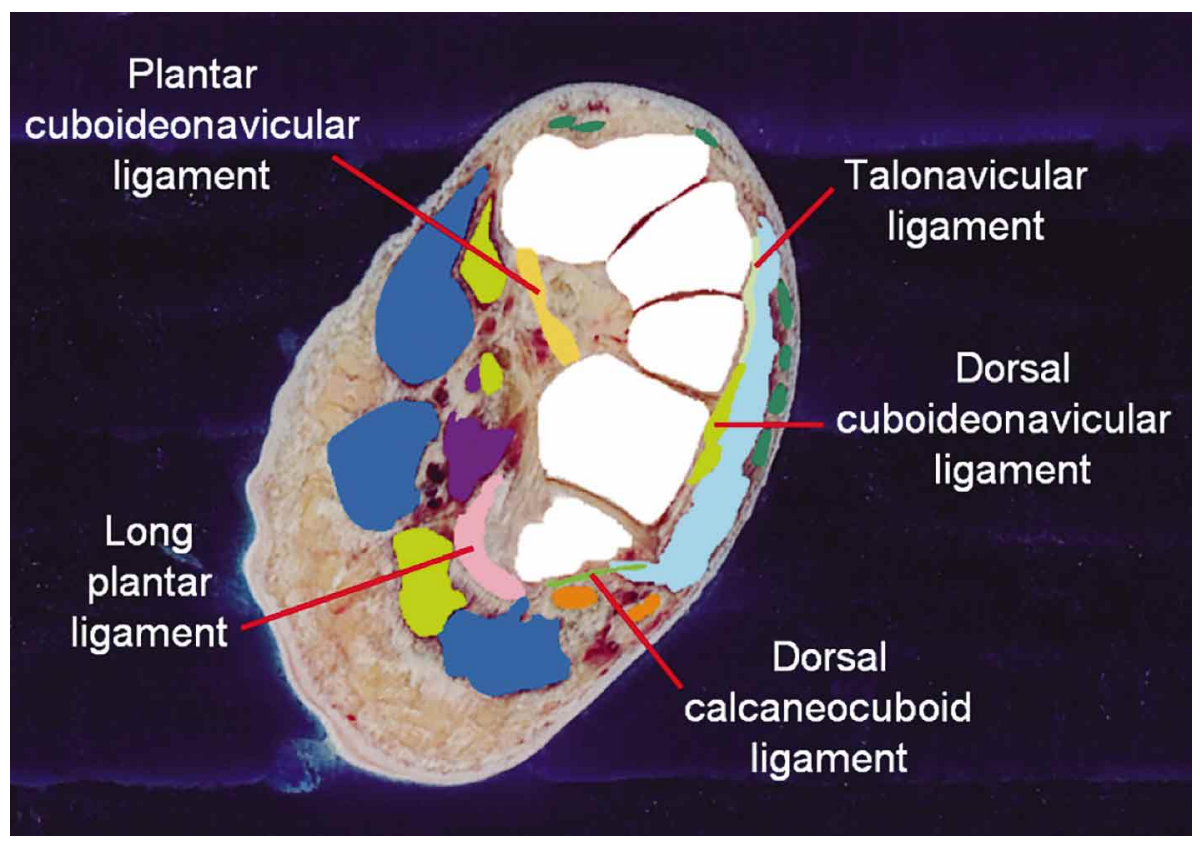

1288 surfaces were suitably reduced in number. The surface models were painted with the same colors used for filling the outlines (Park et al., 2007).

Manufacture of the PDF file. Besides the surface models, two sets of two-dimensional (2D) images were prepared as the material for the PDF file. The first set comprised the original sectioned images, while the second set comprised the color-filled outlines overlapped upon the sectioned images. Each set was selected at $5 \mathrm{~mm}$ intervals, and the two sets were alternative: The first set was numbered 7500 , $7550,7600 \ldots$, and the second set was $7525,7575,7625$, and etc. In the second set, we labeled only the ligaments that were not surface-reconstructed to be less identifiable than bones and muscles (Fig. 1).

Individual models of the skin, bones, and muscles were saved as stereolithography files. The surface models, as well as the arranged plane images, were inputted into a PDF file. The authors employed the inputting method as previously developed and described (Shin et al., 2012a).

After combined display of the 2D and 3D images, any errors of segmentation and surface reconstruction were examined so these could be revised. Initial feature of the PDF file was decided to lay out the models of all bones and muscles with the semitransparent model of the skin (Fig. 2).

In the PDF file, bookmarks were established to exhibit the groups of foot muscles, the anterior, posterior and lateral regions of leg, the dorsum of foot, and the first, second, third, fourth layers of sole (Table I). For the regions of the leg, their surface models appeared in appropriate viewing directions. For the dorsum of foot or sole layers, the models were displayed from the dorsal or plantar view (Fig. 3). Other bookmarks and supplementary movies were composed to demonstrate the five muscles of the ankle and subtalar joints.

Fig. 1. Sectioned image with superimposed color-filed outlines and annotated ligaments. 
Table I. The seventy-one foot structures outlined and surface reconstructed

\begin{tabular}{|c|c|c|}
\hline Systems & Groups & Structures \\
\hline Integumentary (1) & & Skin \\
\hline \multirow[t]{4}{*}{ Skeletal (27) } & Bones of leg (2) & Tibia, Fibula \\
\hline & Tarsal bones (7) & $\begin{array}{l}\text { Talus, Calcaneus, Navicular, Medial cuneiform, Intermediate } \\
\text { cuneiform, Lateral cuneiform, Cuboid }\end{array}$ \\
\hline & Metatarsal bones (5) & First to fifth metatarsal bones \\
\hline & Phalanges (13) & $\begin{array}{l}\text { First to fifth proximal phalanges, Second to fourth middle } \\
\text { phalanges, First to fifth distal phalanges }\end{array}$ \\
\hline \multirow[t]{8}{*}{ Muscular (24) } & Anterior region of leg (4) & $\begin{array}{c}\text { Extensor hallucis longus, Extensor digitorum longus, Fibularis } \\
\text { tertius, Tibialis anterior }\end{array}$ \\
\hline & Posterior region of leg (3) & $\begin{array}{l}\text { Flexor digitorum longus, Flexor hallucis longus, Tibialis } \\
\text { posterior }\end{array}$ \\
\hline & Lateral region of leg (2) & Fibularis longus, Fibularis brevis \\
\hline & Dorsum of foot (2) & Extensor digitorum brevis, Extensor hallucis brevis \\
\hline & First layer of sole (3) & $\begin{array}{l}\text { Abductor hallucis, Abductor digiti minimi, Flex or digitorum } \\
\text { brevis }\end{array}$ \\
\hline & Second layer of sole (3) & $\begin{array}{l}\text { Flex or digitorum longus (tendon), Quadratus plantae, } \\
\text { Lumbricalis }\end{array}$ \\
\hline & Third layer of sole (5) & $\begin{array}{l}\text { Flex or hallucis longus (tendon), Flexor hallucis brevis, Adductor } \\
\text { hallucis (oblique head), Adductor hallucis (transverse head), } \\
\text { Flex or digiti minimi brevis }\end{array}$ \\
\hline & Fourth layer of sole (2) & Plantar interosseus, Dorsal interosseus \\
\hline \multirow[t]{7}{*}{ Articular (19)* } & Inferior tibiofibular joint (2) & Anterior tibiofibular ligament, Posterior tibiofibular ligament \\
\hline & Ankle joint (4) & $\begin{array}{l}\text { Cal caneofibular ligament, Posterior talofibular ligament, } \\
\text { Anterior talofibular ligament, Medial ligament of ankle joint }\end{array}$ \\
\hline & Tarsal ligaments (7) & $\begin{array}{l}\text { Long plantar ligament, Talonavicular ligament, Dorsal } \\
\text { calcaneocuboid ligament, Plantar cuneocuboid ligament, Plantar } \\
\text { cuboideonavicular ligament, Talocalcaneal interosseous } \\
\text { ligament, Dorsal cuboideonavicular ligament }\end{array}$ \\
\hline & Tarsometatarsal joints (1) & Dorsal tarsometatarsal ligament \\
\hline & Intermetatarsal joints (2) & Plantar metatars al ligament, Dorsal metatarsal ligament \\
\hline & Metatarsophalangeal joints (2) & $\begin{array}{c}\text { Collateral ligament of metatars ophalangeal joint, Deep } \\
\text { transverse metatarsal ligament }\end{array}$ \\
\hline & Interphalangeal joints (1) & Collateral ligament of interphalangeal joint \\
\hline
\end{tabular}

Ligaments are just outlined, not surface reconstructed.

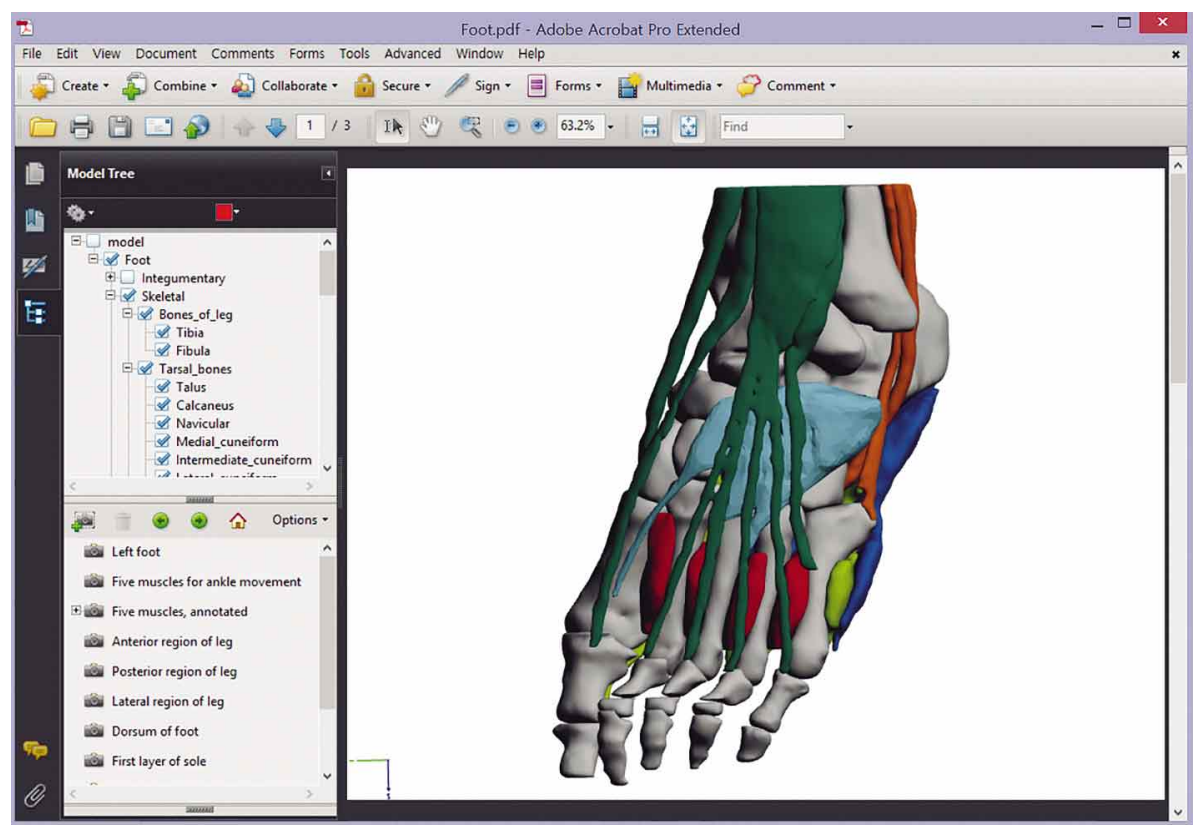

Fig. 2. Initial feature of the PDF file consisting of the model tree window (left top), the bookmarks window (left bottom), and the model display window (right). 


\section{RESULTS}

The prepared PDF file (size 48 MBytes) was downloadable from the Visible Korean site (anatomy.co.kr). Our policy was to use free downloading with no required registration. Using the PDF file on Adobe Reader version 9 (Adobe Systems, Inc., San Jose, CA, USA), the following actions could be tried.

Users were able to generate mixed displays of the surface models using the model tree for their intended choice. When a model was clicked, its anatomical name was highlighted in the model tree (Fig. 2). By manipulating the mouse, the surface models could be freely rotated; they could also be zoomed-in, zoomedout, and shifted. The Adobe Reader toolbar was available for diverse exploration of these surface models (Shin et al., 2012a).
The bookmarks enabled users to look at the required muscle groups without difficulty. Successive selection of the bookmarks of four sole layers gave rise to the visual effect of the sole muscles being stripped in sequence (Fig. 3).

The surface models corresponded with the two-dimensional (2D) images. Clients could select either the pure sectioned images or those with the color-filled outlines, which were even and odd alternatively. On the color-filed outlines, only the ligaments were annotated, but the bones and muscles could be recognized by referring to their surface models. This morphological correlation was accelerated by the authors' intended trial in which the allocated color inside the outlines was the same as the color on the structure's surface model (Fig. 4).
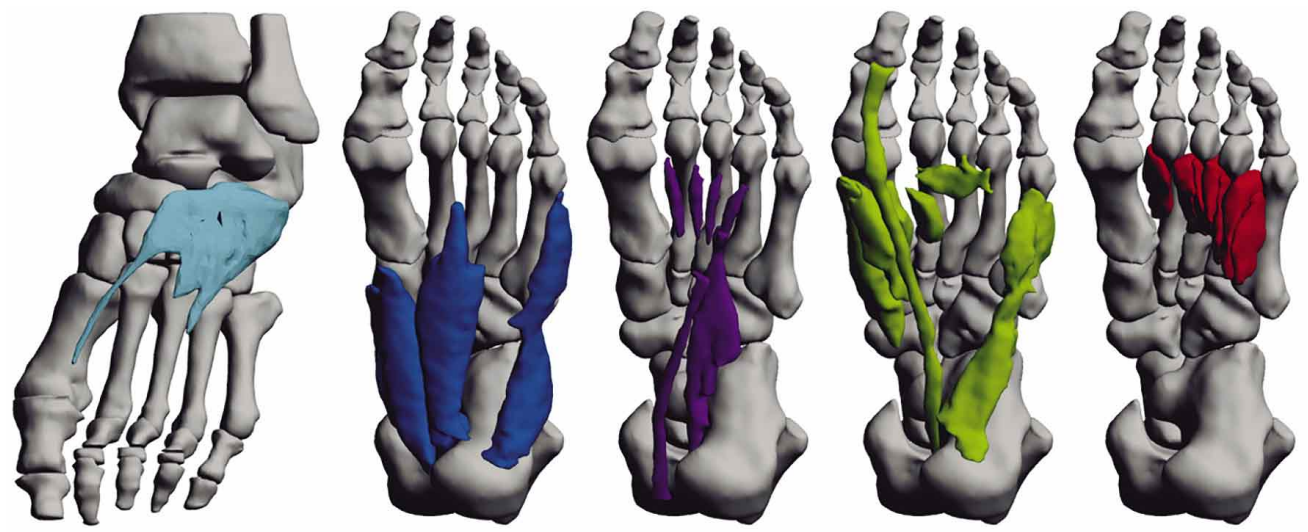

Fig. 3. Surface models showing the dorsum of foot and the four layers of the sole (left to right). These can be immediately seen by the use of bookmarks in the PDF file.

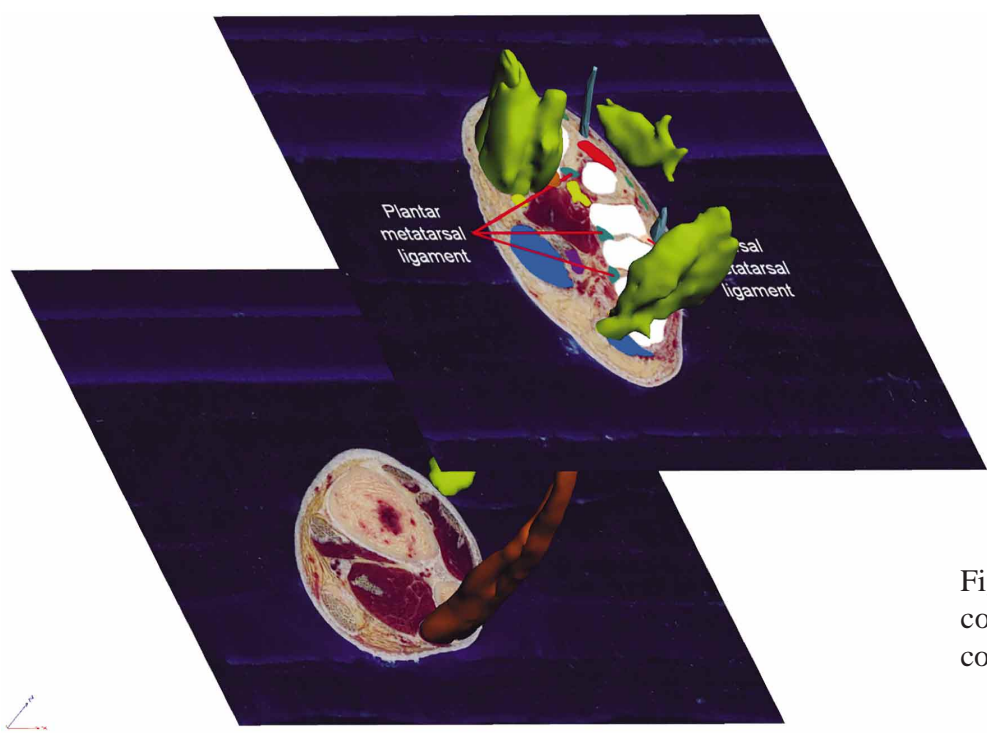

Fig. 4. Sectioned images with or without the color-filled outlines, superimposed on the corresponding surface models. 


\section{DISCUSSION}

The 3D surface models of the foot muscles prepared for this research are expected to contribute to foot anatomy education for the following reasons.

The surface models were made from state-of-theart sectioned images, rather than from computed tomographs or magnetic resonance images (MRIs). So in our former study, using the sectioned images all independent foot muscles could be outlined with ease (Shin et al., 2012a). Consequently, surface models in the PDF file show the origins and insertions of the foot muscles, which encourages users to understand the muscle actions involved (Fig. 3).

Moreover, it is possible to challenge the segmentation of foot ligaments (Figs. 1 and 4). Previously, MRIs of cadaver ankles were examined to study the ligament morphology (Oh et al., 2006). But the MRIs are not enough to recognize full courses of tiny ligaments. In our future research, supplementary ligaments in the sectioned images will be demarcated to yield their satisfactory surface models, which will strengthen the present study because the ligaments enlighten joint movements. The models of both the muscles and ligaments in sole can explain the longitudinal and transverse arches of the foot as well.

Unlike surface models that are stereoscopically drawn like the Zygote Body (zygotebody.com), our models can be positioned on the corresponding sectioned images, both of which reinforce each other. The sectioned images provide detailed morphological information, whereas the surface models explain how the 3D structures look on 2D planes (Fig. 4) (Beyersdorff et al., 2001).
The surface models can be moved to show the muscle actions, especially because they have a small file size, dissimilar to the volume models. By moving each joint with its articular cavity consistent, a reasonable joint axis can be settled on the computer software. These surface models could become the source of a virtual exercise system in which joints are interactively motioned (Yuan et al., 2008).

The 3D models need to be available for viewing off-line. Hollow surface models have a smaller file size than the volume models. However, on-line manipulation of several surface models cannot be done in real-time. An additional issue is that the Internet handling of the surface models requires the installation of a specific plug-in, which is unnecessary for off-line work with the PDF file.

Whole 3D image data can also be extracted from the PDF file by other interested researchers. This is a unique characteristic of this product, because other software packages do not provide their own raw data. Furthermore, investigators worldwide will be supplied with the full data set including the sectioned images, outlined images, and surface models of foot after carrying out an agreement process with the authors. It is hoped that the images presented by authors will thus become a robust resource for virtual dissection for medical students and virtual operation for orthopedic surgeons.

\section{ACKNOWLEDGMENTS}

This work was supported by National Research Foundation of Korea (NRF) Grant funded by the Korean Government (MSIP) (No 2015R1A5A7037630).

JANG, H. G.; CHUNG, M. S. \& SHIN, D. S. Archivos en formato de documento portátil con modelos de superficie para aprender la forma estereoscópica de los músculos del pié. Int. J. Morphol., 33(4):1287-1292, 2015.

RESUMEN: El objetivo de este estudio fue un archivo en formato de documento portátil (PDF) que contiene modelos de superficie estereoscópicas del pie. Mientras que otros modelos de superficie se dibujan subjetivamente sobre la base de los conocimientos anatómicos, nuestros modelos seccionados se reconstruyen a partir de imágenes de alta calidad. A diferencia de otros modelos, nuestro modelo en el archivo PDF también se puede guardar en los computadores de los usuarios individuales para ser manipulados fuera de línea. Se delineó la piel, 27 huesos, 24 músculos, y 19 ligamentos en los pies de un cadáver de sexo masculino del proyecto Visible Korean. Después de apilar los contornos de las estructuras, que no fuera las de los ligamentos, se llevó a cabo la reconstrucción de las superficies. Los modelos de superficie resultantes se colocan en un archivo PDF, en el que los modelos podrían ser superpuestos en cualquiera de las correspondientes imágenes seccionadas o las imágenes de contorno a color. Se establecieron marcadores de PDF para exhibir los grupos de músculos del pie cómodamente. El archivo PDF preparado de esta investigación probablemente sea muy útil para la comprensión de la anatomía topográfica de los músculos del pie. Los modelos que contiene pueden ser extraídos por otros investigadores para la disección o cirugía de visualización virtual de los pies.

PALABRAS CLAVE: Proyectos Humanos Visibles; Pie; Músculos; Imágenes tridimensionales; Procesamiento de imagen asistida por ordenador; Interfaz de usuario-ordenador. 


\section{REFERENCES}

Beyersdorff, D.; Schiemann, T.; Taupitz, M.; Kooijman, H.; Hamm, B. \& Nicolas, V. Sectional depiction of the pelvic floor by CT, MR imaging and sheet plastination: computer-aided correlation and 3D model. Eur. Radiol., 11(4):659-64, 2001.

Kim, B. C.; Chung, M. S.; Kim, H. J.; Park, J. S. \& Shin, D. S. Sectioned images and surface models of a cadaver for understanding the deep circumflex iliac artery flap. $J$. Craniofac. Surg., 25(2):626-9, 2014.

Kumar, P.; Ziegler, A.; Grahn, A.; Hee, C. S. \& Ziegler A. Leaving the structural ivory tower, assisted by interactive 3D PDF. Trends Biochem. Sci., 35(8):419-22, 2010.

Moore, K. L.; Dalley, A. F. \& Agur, A. M. R. Clinically Oriented Anatomy. 7th ed. Philadelphia, Wolters Kluwer/Lippincott Williams \& Wilkins, 2013.

Oh, C. S.; Won, H. S.; Hur, M. S.; Chung, I. H.; Kim, S.; Suh, J. S. \& Sung, K. S. Anatomic variations and MRI of the intermalleolar ligament. AJR Am. J. Roentgenol., 186(4):9437, 2006.

Park, H. S.; Chung, M. S.; Shin, D. S.; Jung, Y. W. \& Park, J. S. Accessible and informative sectioned images, color-coded images, and surface models of the ear. Anat. Rec. (Hoboken), 296(8):1180-6, 2013.

Park, J. S.; Chung, M. S.; Hwang, S. B.; Lee, Y. S.; Har, D. H. \& Park, H. S. Visible Korean Human: improved serially sectioned images of the entire body. IEEE Trans. Med. Imaging, 24(3):352-60, 2005.

Park, J. S.; Shin, D. S.; Chung, M. S.; Hwang, S. B. \& Chung, J. Technique of semiautomatic surface reconstruction of the visible Korean Human data using commercial software. Clin. Anat., 20(8):871-9, 2007.

Phelps, A.; Naeger, D. M. \& Marcovici, P. Embedding 3D radiology models in portable document format. AJR Am. J. Roentgenol., 199(6):1342-4, 2012.

Ruthensteiner, B. \& Hess, M. Embedding 3D models of biological specimens in PDF publications. Microsc. Res. Tech., 71(11):778-86, 2008.

Shin, D. S.; Chung, M. S.; Park, J. S.; Park, H. S.; Lee, S.; Moon, Y. L.; \& Jang, H. G. Portable document format file showing the surface models of cadaver whole body. J. Korean Med. Sci., 27(8):849-56, 2012c.

Shin, D. S.; Jang, H. G.; Hwang, S. B.; Har, D. H.; Moon, Y. L. \& Chung, M. S. Two-dimensional sectioned images and threedimensional surface models for learning the anatomy of the female pelvis. Anat. Sci. Educ., 6(5):316-23, 2013.
Shin, D. S.; Jang, H. G.; Park, J. S.; Park, H. S.; Lee, S. \& Chung, M.S. Accessible and informative sectioned images and surface models of a cadaver head. J. Craniofac. Surg., 23(4):1176-80, 2012a.

Shin, D. S.; Park, J. S.; Park, H. S.; Hwang, S. B. \& Chung, M. S. Outlining of the detailed structures in sectioned images from Visible Korean. Surg. Radiol. Anat., 34(3):235-47, 2012 b.

Yuan, Y.; Qi, L. \& Luo, S. The reconstruction and application of virtual Chinese human female. Comput. Methods Programs Biomed., 92(3):249-56, 2008.

Correspondence to:

Dong Sun Shin

Department of Orthopaedic Biomaterial Science

Osaka University Graduate School of Medicine

2-2 Yamadaoka

Suita

Osaka 565-0871

JAPAN

Email: sdssoft@gmail.com

Received: 18-06-2015

Accepted: 20-08-2015 